\title{
Permeation of Water Contaminative Phenols Through Hairless Mouse Skin
}

\author{
A. S. Huq, ${ }^{1}$ N. F. H. Ho, ${ }^{2}$ N. Husari, G. L. Flynn, ${ }^{3}$ W. E. Jetzer ${ }^{4}$ and L. Condie, Jr. \\ College of Pharmacy, The University of Michigan, Ann Arbor, Michigan 48109-1065 and United States Environmental Protection \\ Agency, 26 West St. Clair St., Cincinnati, Ohio 05268
}

\begin{abstract}
As a means of determining the risk of absorption of water contaminative phenolic compounds through the skin, the permeation of a number of phenols, all on the U.S. Environmental Protection Agency's list of priority pollutants, through hairless mouse skin has been studied, using in vitro diffusion cell methods. Experimentally determined permeability coefficients through intact skin and stratum corneum denuded skin and permeability coefficients derived therefrom for the viable tissue layer and the stratum corneum, which are the tissue's major contributing substrata, have been correlated with their $\log \mathrm{K}_{\mathrm{octanol} / \text { water }}$ partition coefficients. Permeability coefficients for the whole skin and the stratum corneum systematically increased with increasing phenol lipophilicity to limiting values of about 0.15 and $0.30 \mathrm{~cm} / \mathrm{hr}$, respectively. The values of the permeability coefficients for the viable tissue were roughly the same for all compounds $(\approx 0.36 \mathrm{~cm} / \mathrm{hr})$. Because of the inductive effects of $\mathrm{Cl}$ and $\mathrm{NO}_{2}$ substituents on the aromatic ring, phenolic analogs containing these moieties are acidic and, consequently, their overall skin permeabilities were highly $\mathrm{pH}$-dependent in the range of $\mathrm{pH}$ values seen for surface waters. High fluxes were noted for such phenols at low $\mathrm{pH}$, where they exist essentially in a non-ionized state. Though low, fluxes of the compounds were measur-
\end{abstract}

\footnotetext{
Current addresses:

${ }^{1}$ Squibb Institute for Medical Research, P. O. Box 191, New Brunswick, NJ 08903.

${ }^{2}$ Pharmacy Research Unit, The Upjohn Co., Kalamazoo, MI 49001.

${ }^{3}$ To whom all correspondence should be addressed.

${ }^{4}$ Kantonsspital Bruderholz Pharmaceutical Department, CH-4101 Bruderholz BL, Switzerland.
}

able at $\mathrm{pH}$ 's $\gg \mathrm{pK}_{\mathrm{a}}$ 's, indicating that phenolic anions also pass through the skin. With the exceptions of relatively polar phenol and the mono-nitro phenols, the free acid forms of all the phenols studied permeated skin with ease and at rates approaching those of denuded skin. The intact skin permeability coefficient of the free acid form of 4 . nitro phenol was exceptionally low, which suggests that it might associate intermolecularly.

Certain toxic compounds are found as contaminants of industrial waste streams and migrate into the aquifer and national watershed. By and large, it is unclear what risk trace levels of these pollutants present to individuals who unsuspectingly drink or bathe in the contaminated waters. The relative risk of absorption of such agents through the skin is especially difficult to put into proper perspective as the kinetics of skin permeation are unknown for all but a few of the compounds of interest. More than 100 compounds, many of them phenols, have been identified by the United States Environmental Protection Agency as significant waterborne pollutants and the potential extent of skin absorption relative to the potential of uptake by other modes of exposure needs to be established.

The present study deals with pollutant phenols and was undertaken: (a) to determine the kinetics of skin permeation of phenol and certain of its analogs, (b) to investigate the $\mathrm{pH}$ dependency of the permeability of these compounds, (c) to put these compounds into a structure-permeability framework for eventual toxic risk assessment of all compounds of structural similarity and, finally, (d) to provide estimates of the possible skin uptake of the investigated compounds. The studies were made 
with hairless mouse skin as the model skin for the assessment of the permeation kinetics. Permeability studies, using whole and stripped skin, were done to determine the separate diffusional resistance contributions of the stratum corneum and viable tissue layer to the skin permeation of each compound.

\section{Experimental}

\section{Materials}

Phenolic compounds of analytical grade quality included phenol, 4-nitrophenol, 2,4-dinitrophenol, 2-chlorophenol, 2,4-dichlorophenol, 2,4,6-trichlorophenol, 2,4-dimethylphenol and 4-chloro3 -cresol. Tritium-labeled phenol and 4-nitrophenol were purchased and used as received. Reagent grade buffer chemicals included citric acid $\cdot 1 \mathrm{H}_{2} \mathrm{O}$, disodium phosphate anhydrous, monosodium phosphate $\cdot 1 \mathrm{H}_{2} \mathrm{O}$, sodium chloride, sodium hydroxide and hydrochloric acid. Citrate-phosphate buffers were prepared for solutions between $\mathrm{pH} 2.0-4.5$ and phosphate buffers for solutions between $\mathrm{pH} 4.5$ and 8.0 .

The compositions of the buffers were as follows:

\begin{tabular}{lc} 
a) Citric Acid $\cdot 1 \mathrm{H}_{2} \mathrm{O}$ & $11.58 \mathrm{~g}$ \\
$\mathrm{Na}_{2} \mathrm{HPO}$ & \\
$\mathrm{NaCl}$ & $12.75 \mathrm{~g}$ \\
$\mathrm{NaOH}(2 \mathrm{~N})$ & $0.35 \mathrm{mg}$ \\
Distilled water, up to & $-3.00 \mathrm{~L}$ \\
\hline
\end{tabular}

$\mathrm{HCl} 6 \mathrm{~N}$ was added, if necessary, to get a desired $\mathrm{pH}$.

b) Phosphate buffers:

$\begin{array}{lc}\mathrm{NaH}_{2} \mathrm{PO}_{4} \cdot \mathrm{H}_{2} \mathrm{O} & 9.195 \mathrm{~g} \\ \mathrm{NaCl} & 4.45 \mathrm{~g} \\ \mathrm{NaOH} 2 \mathrm{~N} & \sim 30 \mathrm{~L} \\ \text { Distilled water, up to } & 1 \mathrm{~L}\end{array}$

$\mathrm{HCl}(6 \mathrm{~N})$ was added, if necessary, to get a desired $\mathrm{pH}$. All prepared buffer solutions were iso-osmotic with physiologic fluids.

\section{Skin Preparation}

Hairless mice (SKH-hr-1 strain), 60-100 days old, were used in this study. After sacrificing a mouse by spinal cord dislocation, its abdominal skin was wiped clean with a tissue moistened with normal saline. Rectangular sections of whole skin (or skin stripped of its stratum corneum) several $\mathrm{cm}$ in each dimension were excised with surgical scissors. Adhering fat and other visceral debris were removed carefully from the undersurface with tweezers. The excised skin was trimmed into oversized circles and mounted in a two-compartment diffusion cell whose construction and operation have been detailed earlier (Durrheim et al. (1980)).

For some of the studies, the hairless mouse skin was stripped repeatedly ( 20 times) with cellophane tape to remove the stratum corneum. Substantial previous experience showed this to be sufficient stripping to functionally eliminate the stratum corneum's diffusional resistance. Each stripping was performed with fresh tape. The tape was placed firmly against the abdominal surface of a freshly sacrificed mouse and then peeled away.
After the first several sirippings, the skin became more and more an oozing surface with each succeeding peeling.

\section{Skin Permeation Method}

The skin sections as described above were mounted carefully between the half-cells of the diffusion cell and fastened with a spring clamp. The two half-cells were filled with normal saline, the whole system was immersed in a waterbath $\left(37^{\circ} \mathrm{C}\right)$ and the stirring motors were connected. After the cell compartments were rinsed with normal saline, the donor compartment was charged with appropriate concentrations of the permeant; the complete donor solution was carefully removed and replaced with a concentration solution of a phenol (UV assays) or $100 \mu \mathrm{L}$ was removed and replaced with an equal volume of a radiochemical concentrate. Stirring set at $150 \mathrm{rpm}$ was initiated. At predetermined times, samples were withdrawn from the receiver compartment and analyzed by direct UV spectrophotometry, high pressure liquid chromatography (HPLC) with UV detection, or liquid scintillation spectrometry. Each sample was replaced with fresh saline with correction of the receiver concentration for the dilution of sampling. Samples were taken from the donor compartment at the beginning and end of each experiment to check for mass balance.

With the exceptions of phenol and 2,4-dinitrophenol, the phenols were assayed spectrophotometrically with a Beckman model DK-2A spectrophotometer and samples were withdrawn at predetermined times and absorbances measured at: 2-chlorophenol, $273 \mathrm{~nm}$; 2,4-dichlorophenol, $245 \mathrm{~nm}$; 2,4,6-trichlorophenol, $245 \mathrm{~nm}$; $p$-chloro-m-cresol, $245 \mathrm{~nm}$; 2-nitrophenol, 414 $\mathrm{nm}$; 4-nitrophenol, $400 \mathrm{~nm}$ and 2,4-dimethylphenol, $414 \mathrm{~nm}$. Samples were diluted for analysis, if necessary.

An HPLC assay system with a Waters model M-45 pump, Gilson model PWS2107FL holochrome detector and Micrometrics model 725 autoinjector was used to assay 2,4-dinitrophenol samples. The column was a reversed phase RP-18 (10 $\mu \mathrm{m}), 25 \mathrm{~cm} \times 4.6 \mathrm{~mm}$. The mobile phase was $50 \%$ acetate buffer (pH 4.3), 40\% methanol and $10 \%$ water. $720 \mathrm{~nL}$ samples were withdrawn at predetermined times and assayed with necessary dilutions. Detection wavelength was set at $254 \mathrm{~nm}$.

For radiolabelled phenol, $200 \mu \mathrm{L}$ samples were withdrawn at predetermined times and added to $10 \mathrm{~mL}$ of aqueous counting scintillant (Amersham) and counts per minute were obtained with a Beckman LS 9000 liquid scintillation counter. For permeability-pH studies, the 4-nitrophenol was radiolabelled. The sample size and assay procedure were the same for phenol.

With the exception of permeability-pH studies with 4-nitrophenol, 2,4-dinitrophenol and 2,4,6-trichlorophenol, the receiver side $\mathrm{pH}$ was kept at 6.1 , the $\mathrm{pH}$ of unbuffered normal saline. For the permeability-pH studies with 4-nitrophenol, 2,4-dinitrophenol and 2,4,6-tricholorophenol, the receiver side $\mathrm{pH}$ was maintained at 7.6 with phosphate buffer. With the exception of the $\mathrm{pH}$-permeability studies, where donor $\mathrm{pH}$ was deliberately varied, the donor $\mathrm{pH}$ was maintained at $\mathrm{pH}<\mathrm{pKa}$ of each compound with either citrate-phosphate or phosphate buffers.

\section{Estimation of Permeability Coefficient in Whole and Stripped Skin from Experimental Data}

Effective permeability coefficients $\left(\mathrm{P}_{\mathrm{e}}, \mathrm{cm} / \mathrm{hr}\right)$ were calculated from quasi-steady state fluxes according to: 


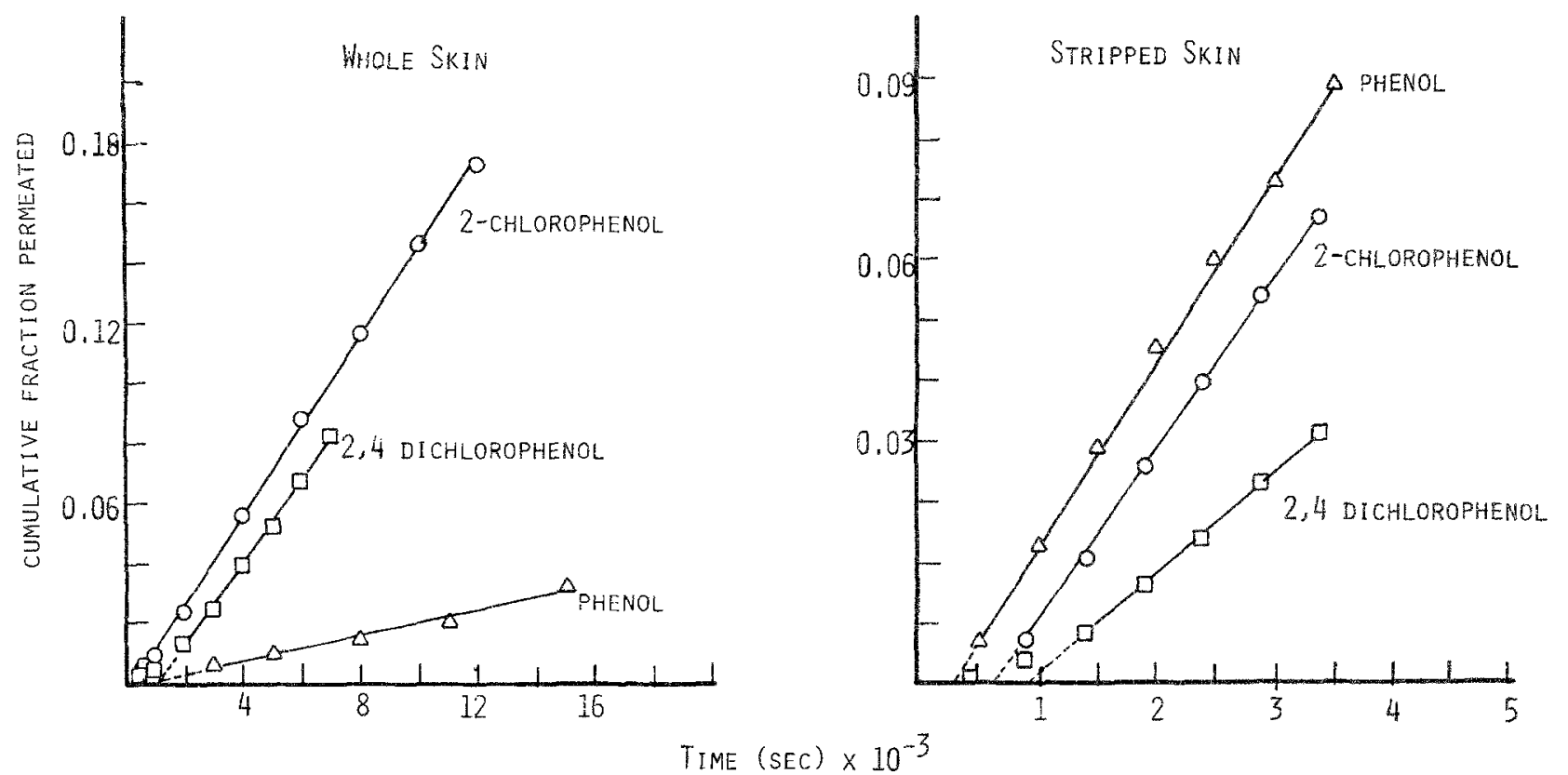

Fig. 1. Appearance kinetics of phenol and chloro-analogs in dilute solutions across whole skin and stripped skin; presented in terms of cumulative fractions of the applied phenols which have permeated to the receiver compartment

$$
P_{e}=\frac{V}{A C_{D}} \cdot\left(\frac{d C_{R}}{d \hat{t}}\right)
$$

where

$$
\begin{aligned}
& \mathrm{P}_{\mathrm{e}}=\text { effective permeability coefficient } \\
& \mathrm{A} / \mathrm{V}=\text { ratio of the diffusional area to receiver-side volume } \\
& \mathrm{C}_{\mathrm{D}}=\text { initial concentration of permeant in the donor } \\
& \mathrm{dC}_{\mathrm{R}} / \mathrm{dt}=\text { steady-state appearance rate in the receiver }
\end{aligned}
$$

Sink conditions were maintained in the receiver by keeping the concentration at an inconsequential fraction of the donor concentration.

The steady-state exchange method developed previously for permeation studies with $n$-alkanol homologs (Flynn et al. (1981)) was also employed to obtain a separate estimate of the effective permeability coefficient 2,4 dichlorophenol. After multiple exchanges, effective permeability coefficients were calculated for the ninth exchange from donor depletion and receive accumulation data respectively from:

$$
\ln \frac{C_{D, t}}{C_{D, O}}=-\frac{A P_{e} \Delta t}{V}
$$

and

$$
\frac{\Delta C_{R}}{\Delta t}=\frac{A P_{e}}{V}\left(\bar{C}_{D}-\bar{C}_{R}\right)
$$

where

$$
\begin{aligned}
\mathrm{C}_{\mathrm{D}, \mathrm{O}} \mathrm{C}_{\mathrm{D}, \mathrm{t}}= & \text { donor concentrations at the beginning and end of } \\
& \text { each exchange, respectively } \\
\widehat{\mathrm{C}}_{\mathrm{D}}, \overrightarrow{\mathrm{C}}_{\mathrm{R}}= & \begin{array}{l}
\text { average donor and receiver concentrations } \\
\end{array} \\
& \text { during a given exchange, respectively } \\
\Delta \mathrm{C}_{\mathrm{R}} / \Delta \mathrm{t}= & \begin{array}{l}
\text { increase in receiver cuncentration per exchange } \\
\text { period }
\end{array} \\
\Delta \mathrm{t}= & \text { exchange interval }
\end{aligned}
$$

\section{Results}

Figure 1 shows the appearance of phenol and two chlorophenols in the receiver chamber with time. The kinetic profiles are typical for the range of chemical pollutants covered within this report. Steady states in permeation were reached in time and permeability coefficients were calculated from the steady state (technically, quasi-steady state) fluxes. In theory, retention of permeant within a membrane must be small and insignificant for one to calculate true permeability coefficients from quasi-steady state data; it was suspected that this condition might not be met for the more lipophilic phenols. Therefore, an exchange method, developed previously for homologous alkanols (Flynn et al. (1981)) which effectively cancels the effects of membrane permeant retention, was used to independently assess the permeability coefficient of 2,4-di-chlorophenol (Figure 2). Steady rates of membrane uptake and output were obtained after multiple exchanges. Moreover, mass balance anal$y$ sis indicated the amount of solute leaving the donor chamber of the diffusion cell was essentially equivalent to the amount appearing in the receiver chamber after a half dozen exchanges. Effective permeability coefficients calculated for the ninth interval from donor depletion and receiver accumulation were 0.40 and $0.32 \mathrm{~cm} / \mathrm{hr}$, respectively. The average of these, $0.36 \mathrm{~cm} / \mathrm{hr}$, was several-fold larger than the value of $0.125 \mathrm{~cm} / \mathrm{hr}$ determined by 


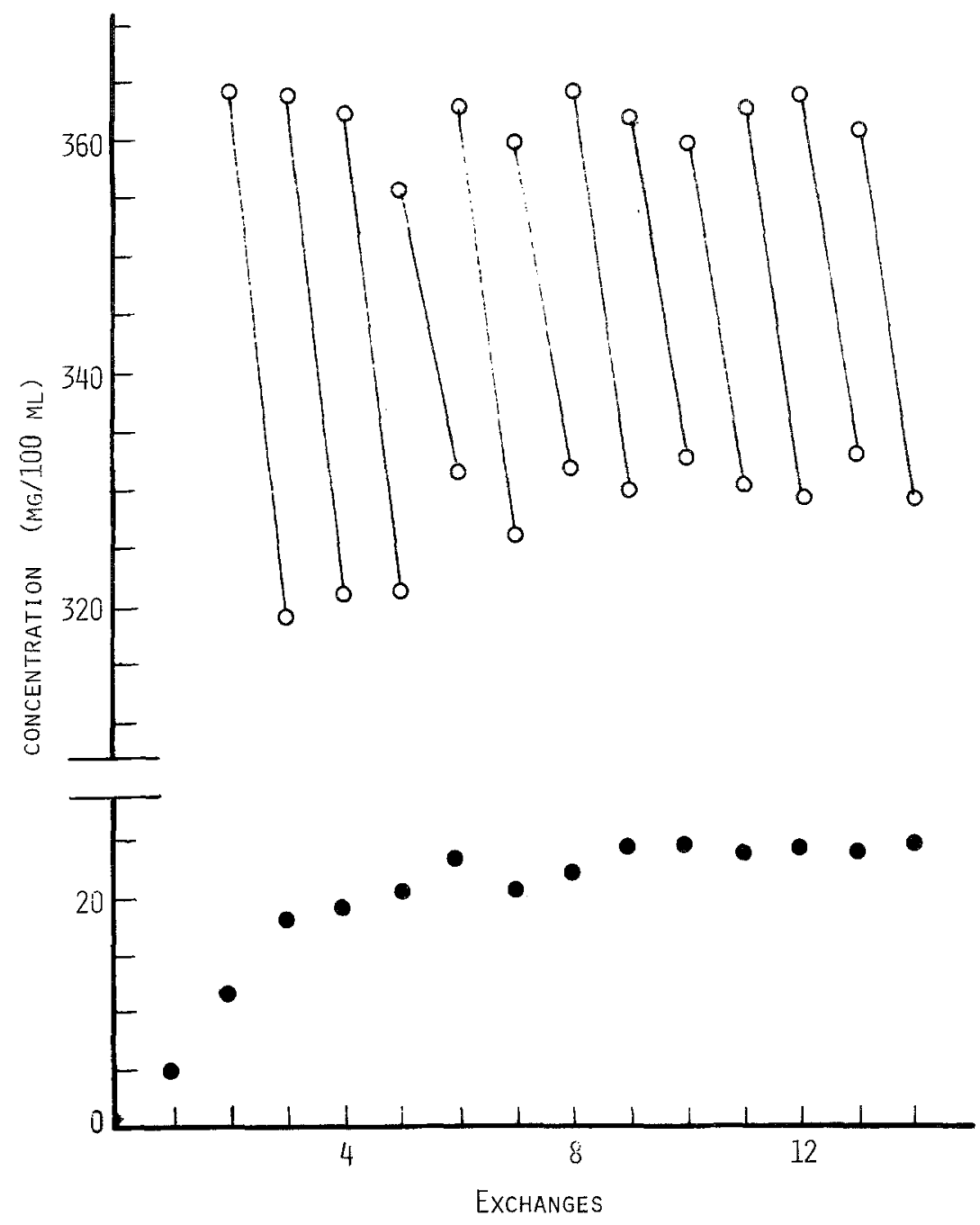

Fig. 2. Exchange method for 2,4dichlorophenol over 2,000 sec intervals. Data $(O)$ connected with a line represents the concentrations of the donor side at the beginning and end of each interval. Single point (-) represents the concentration of the receiver side of the end of an interval the standard permeation procedure (Table 1). Although this indicated that sufficient 2,4-di-chlorophenol was retained in the skin to effect the estimated permeability coefficient by the conventional method, the effect of retention was not exaggerated. Since actual absorption rates of the phenols will also be affected by membrane retention, conventionally derived permeability coefficents are, nevertheless, the most appropriate for risk estimation.

Permeability coefficients through intact hairless mouse skin obtained under the condition that $\mathrm{pH}<$ $\mathrm{pK}$ for each phenol are given in Table 1; studies for several of the phenols were performed as a function of concentration initially placed in the donor chamber. Similarly, data for denuded skin (20 times stripped skin) are given in Table 2. Tables 1 and 2 show that, except where $\mathrm{pH}$-effects themselves were being explored, permeability coefficients were assessed for stripped and whole skin under conditions which kept ionization to a minimum.
Consequently, the bulk of the data represent intrinsic permeabilities of the non-electrolyte forms. Unbuffered normal saline was generally used as the receiver medium; any receiver ionization favorably influenced sink conditions and, therefore, could be ignored. Data gathered to explore the $\mathrm{pH}$-permeability sensitivities of 4-nitrophenol, 2,4-dinitrophenol and 2,4,6-trinitrophenol are given in Table 3. These data were obtained with the receiver buffered to $\mathrm{pH} 7.6$ (phosphate), which distinguishes them from the data in Tables 1 and 2, for which the receiver medium was unbuffered saline, nominally at a $\mathrm{pH}$ of 6 .

An early concern in this work was whether the phenols could enhance their own permeabilities by denaturing the stratum corneum, as is known to happen with phenol (Roberts et al. $(1977,1978)$ and Behl et al. (1983). At trace radiolable concentrations, phenol's permeability coefficient (Table 1) was the same as previously reported (Behl et al. (1983)) but, as also shown previously, phenol at 
Table 1. Permeability of phenolic compounds through whole skin

\begin{tabular}{|c|c|c|c|c|c|}
\hline Permeant & $\mathrm{pK}_{\mathrm{a}}^{\mathrm{a}}$ & $\begin{array}{l}\text { Donord } \\
\mathrm{pH}\end{array}$ & $\begin{array}{l}\text { Concentration } \\
(\mathrm{g} / 100 \mathrm{~mL})\end{array}$ & $\begin{array}{l}\text { Permeability } \\
\text { coefficient, } \mathrm{P}_{\mathrm{e}} \\
\text { Apparent } \\
( \pm \mathrm{s} . \mathrm{d} .) \times 10^{3} \\
(\mathrm{~cm} / \mathrm{hr})\end{array}$ & $\begin{array}{l}\text { Average } \\
\text { lag time } \\
\text { (min) }\end{array}$ \\
\hline \multirow[t]{2}{*}{ Phenol } & 9.92 & 5.82 & 3.30 & 171. $(12.3)$ & 10.3 \\
\hline & & 6.19 & Trace & $18.8(3.0)$ & 10.5 \\
\hline \multirow{3}{*}{ 4-Nitrophenol } & 7.15 & 3.46 & 0.05 radiochemical assay & $12.7(2.8)$ & 35.3 \\
\hline & & & 0.50 UV assay & $20.9(1.2)$ & $30.3(6.4)$ \\
\hline & & & 0.05 UV assay & $23.1(2.2)$ & $8.3(3.3)$ \\
\hline 2-Nitrophenol & 7.17 & 3.46 & 0.05 & 101. (6.9) & 4.2 \\
\hline \multirow[t]{3}{*}{ 2-Chlorophenol } & 8.49 & 5.25 & 0.50 & 140. (13.5) & 6.3 \\
\hline & & 5.50 & 0.19 & 116. $(9.5)$ & 10.3 \\
\hline & & 5.74 & 0.05 & 107. (10.5) & 21.9 \\
\hline \multirow[t]{4}{*}{ 2,4-Dichlorophenol } & 7.85 & 5.15 & 0.40 & 125. $(5.6)$ & 18.9 \\
\hline & & 5.15 & 0.40 & $361 .^{c}$ & - \\
\hline & & 5.30 & 0.20 & 107. $\quad(9.0)$ & 23.2 \\
\hline & & 5.54 & 0.05 & 115. (12.7) & 32.0 \\
\hline 2,4-Dinitrophenol & 3.96 & 2.0 & 0.05 & 151 & 21.5 \\
\hline 2,4-Dimethylphenol & $10.59^{\mathrm{b}}$ & 6.31 & 0.05 & 110 & 10.1 \\
\hline \multicolumn{6}{|l|}{ 4-Chloro-3-methyphenol } \\
\hline (p-chloro-m-cresol) & $9.56^{\mathrm{b}}$ & 6.18 & 0.05 & 119. (1.8) & 35.8 \\
\hline $2,4,6$-Trichlorophenol & 6.0 & 5.0 & 0.05 & 174. $\quad(1.0)$ & 29.7 \\
\hline
\end{tabular}

Literature values found in Barlin and Perrin (1966)

- Calculated from Hammett $\sigma$ constants

c Average of the two methods of assessment by the exchange method (see text)

${ }^{d}$ The receiver $\mathrm{pH}$ was 6.2 in all experiments ( $\mathrm{pH}$ of the unbuffered, normal saline)

Table 2. Permeability coefficients of phenolic compounds through stripped skin

\begin{tabular}{|c|c|c|c|c|}
\hline Permeant & $\begin{array}{l}\text { Concentration } \\
(\mathrm{g} / 100 \mathrm{~mL})\end{array}$ & $\begin{array}{l}\text { Donor } \\
\mathrm{pH}\end{array}$ & $\begin{array}{l}\text { Permeability } \\
\text { coefficient of } \\
\text { Stripped Skin, } P_{\mathrm{ss}} \\
( \pm \mathrm{s} \text {.d. }) \times 10^{3} \mathrm{~cm} / \mathrm{hr}\end{array}$ & $\begin{array}{l}\text { Lag time } \\
\text { (min) }\end{array}$ \\
\hline Phenol & Trace & 6.19 & $264(22)$ & 3.7 \\
\hline \multirow[t]{2}{*}{ 4-Nitrophenol } & 0.500 & 3.4 & $173(27)$ & 6.7 \\
\hline & 0.050 & 3.46 & $257(11)$ & 2.7 \\
\hline \multirow[t]{3}{*}{ 2-Chlorophenol } & 0.496 & 5.25 & $214(30)$ & 8.5 \\
\hline & 0.186 & 5.50 & $276(28)$ & 5.5 \\
\hline & 0.049 & 5.7 & $253(4.7)$ & 13.5 \\
\hline \multirow[t]{2}{*}{ 2,4-Dichlorophenol } & 0.400 & 5.15 & $136(15)$ & 3.3 \\
\hline & 0.050 & 5.54 & $154(23)$ & 16.9 \\
\hline 4-Chloro-3-cresol & 0.055 & 6.2 & $241(22)$ & 14.6 \\
\hline 2,4-Dinitrophenol & 0.041 & 2.0 & $44(34)$ & 2.6 \\
\hline
\end{tabular}

a The $\mathrm{pH}$ values are the same as for the whole skin when identical concentrations were used. As with whole skin, the receiver $\mathrm{pH}$ was 6.2 , the $\mathrm{pH}$ of unbuffered normal saline, in all cases

high concentration, in this case $3.3 \% \mathrm{~W} / \mathrm{V}$, permeated roughly ten times faster due to horny layer impairment. In contrast, the permeability coefficient of 2-chlorophenol was assessed over a tenfold range of concentration with an upper concentration of $0.5 \%$. While the value of $0.140 \mathrm{~cm} / \mathrm{hr}$ at $0.5 \%$ is significantly greater than the value of 0.107 $\mathrm{cm} / \mathrm{hr}$ at $0.05 \%$ (t-test, $0.1>\mathrm{P}>0.05$ ), the absolute difference was not large. The value obtained at $0.19 \%$ falls between these values and is not signifi- cantly different from either. For 2,4-dinitrophenol, the $0.4 \%$ solution permeability coefficient, 0.125 $\mathrm{cm} / \mathrm{hr}$, is significantly greater than the $0.2 \%$ value, $0.107 \mathrm{~cm} / \mathrm{hr}(0.025>\mathrm{P}>0.125)$ and the $0.05 \%$ value of $0.115 \mathrm{~cm} / \mathrm{hr}(0.15>\mathrm{P}>0.1)$. Despite these differences, the effect of concentration on permeability is nominal, no doubt due to the fact that these latter phenols experience relatively little diffusional resistance in the unimpaired stratum corneum to begin with. Because of the limited nature 
Table 3. Permeability of selected phenols as function of $\mathrm{pH}$

\begin{tabular}{|c|c|c|c|c|c|}
\hline Permeant & $\mathrm{pK}^{\mathrm{a}}$ & $\begin{array}{l}\text { Donor } \\
\mathrm{pH}\end{array}$ & $\begin{array}{l}\text { Concentration } \\
(\mathrm{g} / 100 \mathrm{~mL})\end{array}$ & $\begin{array}{l}\text { Appare } \\
( \pm) \text { s.d } \\
\mathrm{cm} / \mathrm{hr}\end{array}$ & $\begin{array}{l}\text { ent } P_{e} \\
\times 10^{3}\end{array}$ \\
\hline \multirow[t]{4}{*}{ 4-Nitrophenol } & 7.15 & 3.46 & 0.05 & 12 & $(2.8)$ \\
\hline & & 6.20 & 0.05 & 11 & (1.3) \\
\hline & & 7.56 & 0.05 & 7 & $(0.7)$ \\
\hline & & 10.16 & 0.05 & 0.5 & $(0.1)$ \\
\hline \multirow[t]{7}{*}{ 2,4-Dinitrophenol } & 3.96 & 2.0 & 0.05 & 151 & \\
\hline & & 3.5 & 0.05 & 116 & \\
\hline & & 3.5 & 0.05 & 105 & $(18.2)$ \\
\hline & & 4.35 & 0.05 & 50.6 & \\
\hline & & 4.65 & 0.05 & 32.6 & (2.3) \\
\hline & & 6.0 & 0.05 & 3.15 & \\
\hline & & 7.7 & 0.05 & 0 & \\
\hline \multirow[t]{3}{*}{ 2,4,6-Trichlorophenol } & 6.0 & 5.0 & 0.05 & 174 & \\
\hline & & 6.0 & 0.05 & 87 & \\
\hline & & 7.4 & 0.05 & 40.9 & $(4.0)$ \\
\hline
\end{tabular}

a Literature values found in Barlin and Perrin (1966)

${ }^{b}$ Receiver pH was maintained at 7.6 with phosphate buffer

of these effects, it was decided that no appreciable concentration artifact would be introduced, so long as the concentrations of the phenols were kept low, and all subsequent work was at $0.05 \%$ or lower concentration.

Lag times are recorded in Tables 1 and 2. These were determined by extrapolating the steady state lines to the time axis in the usual way. Such values are notoriously sensitive to experimental error and, therefore, must be considered very approximate. In addition, while lag times have a straightforward relationship to diffisivity for simple isotropic membranes in the absence of boundary layer influences, the interdependencies of lag times, diffusion coefficients and sorptive binding constants in membranes as complex as the skin is totally obscure. Therefore, no attempt was made to reduce lag times to effective diffusivities. It is merely pointed out that lag times for the phenols are of short duration, with a few marginally longer than 30 min and most less than 20 min. This simply means diffusive gradients of the phenols are quickly established across the skin and the onset of absorption is well within the usual times swimmers spend in a pool or lake and even within the times taken by some to bathe or shower.

\section{Discussion}

The present work concerns the permeability of known water contaminative phenols through skin and potential risk which attends bathing, swim- ming, or other direct skin contact with phenol-polluted water. In making the risk assessments for the phenols, one has to account for the weak electrolyte nature of phenols in general and for the possible ability such compounds have to impair the skin barrier as revealed in other work (Roberts et al. (1977, 1978) and Behl et al. (1983)). Thus, aspects of the studies involve assessing $\mathrm{pH}$ effects on permeability and, to a more limited extent, concentration dependencies of permeability of some phenolic prototypes. Special emphasis has been placed on how permeability relates to lipophilicity of the free acid forms of the respective phenols.

\section{Strata Permeability and Relationship to Permeant Lipophilicity}

For all of the phenols, except 2,4-dimethylphenol and 2,4,6-trichlorophenol, data were obtained on skin sections from which the stratum corneum was removed by adhesive tape stripping (Flynn et al. (1981)) (Behl et al. (1983, 1984)). Permeability coefficients obtained on stripped skin were larger than found for whole skin but the degree to which removal of the horny layer raised the permeability was exceedingly variable. Phenol and 4-nitrophenol experienced 15 -fold increases in permeability coefficients while, at the other extreme, the permeability coefficients of 2-chlorophenol, 2,4-dichlorophenol and 4-chloro 3-methylphenol were less than doubled.

The permeability coefficient of the stratum cor- 
Table 4. Permeability coefficients for whole skin, viable tissue and stratum corneum

\begin{tabular}{|c|c|c|c|c|}
\hline Permeant & $\begin{array}{l}\text { Experimental } \\
\text { permeability } \\
\text { coefficient, } \\
\text { whole skin } \\
\mathrm{P}_{\mathrm{e}} \times 10^{3} \\
(\mathrm{~cm} / \mathrm{hr})^{\mathrm{a}}\end{array}$ & $\begin{array}{l}\text { Estimate of } \\
\text { viable tissue } \\
\text { permeability } \\
\text { coefficient } \\
\mathrm{P}_{\mathrm{vt}} \times 10^{3}\end{array}$ & $\begin{array}{l}\text { Estimated } \\
\text { stratum corneum } \\
\text { permeability } \\
\mathrm{P}_{\mathrm{sc}} \times 10^{3} \\
(\mathrm{~cm} / \mathrm{hr})\end{array}$ & $\log \mathrm{PC}^{\mathrm{b}}$ \\
\hline Phenol & 18.8 & 338. & 20.2 & 1.46 \\
\hline 2,4-Dinitrophenol & 151. & 705. & 228 & 1.52 \\
\hline 2-Nitrophenol & 101. & - & - & 1.77 \\
\hline 4-Nitrophenol & $22^{\mathrm{d}}$ & 327. & $25.4^{\mathrm{d}}$ & 1.96 \\
\hline 3-Nitrophenol & - & - & - & 2.00 \\
\hline 2-Chlorophenol & 106. & 320. & 182. & 2.15 \\
\hline 2,4-Dimethylphenol & 110. & - & - & 2.30 \\
\hline 4-Chlorophenol & - & - & - & 2.39 \\
\hline 2,4-Dichlorophenol & $\begin{array}{c}115 . \\
(361 .)^{\mathrm{c}}\end{array}$ & 177. & $\begin{array}{l}453 . \\
(*)\end{array}$ & 3.08 \\
\hline 4-Chloro-3-cresol & 119. & 302. & 235 . & 3.10 \\
\hline 2,4,6-Trichlorophenol & 174. & - & - & 3.69 \\
\hline
\end{tabular}

neum can be assessed by difference from the two sets of data and knowledge of the total boundary layer resistance of the diffusion cell. The latter is known (Flynn et al. 1981) for the cells in question. The total resistance of the laminate, the reciprocal of the effective permeability coefficient, $\mathrm{P}_{\mathrm{e}}$, is described by a series of resistances as (Flynn et al. (1981)):

$$
\frac{1}{\mathrm{P}_{\mathrm{e}}}=\frac{1}{\mathrm{P}_{\mathrm{sc}}}+\frac{1}{\mathrm{P}_{\mathrm{vt}}}+\frac{2}{\mathrm{P}_{\mathrm{aq}}}=\frac{1}{\mathrm{P}_{\mathrm{sc}}}+\frac{1}{\mathrm{P}_{\mathrm{ss}}}
$$

where

$$
\begin{aligned}
& \mathrm{P}_{\mathrm{e}}=\text { effective permeability coefficient of the } \\
& \mathrm{P}_{\mathrm{ss}}=\text { permeability coefficient of the stripped } \\
& P_{s c}=\text { permeability coefficient of the isolated } \\
& \text { stratum corneum layer } \\
& P_{v t}=\text { permeability coefficient of the isolated vi- } \\
& P_{a q}=\text { permeability coefficient of an aqueous }
\end{aligned}
$$

The $\mathrm{P}_{\mathrm{aq}}$ value determined previously is $2.4 \mathrm{~cm} / \mathrm{hr}$. Note the actual permeability coefficient of the viable tissue layer, $P_{v t}$, is estimated from the permeability coefficients of stripped skin given in Table 2 by correcting them for the aqueous boundary layers. One estimates $P_{s c}$, the stratum corneum permeability coefficient, directly from the difference in whole skin and stripped data. The overall perme- ability coefficient and the derived values for $\mathrm{P}_{\mathrm{sc}}$ and $P_{\mathrm{vt}}$ are given in Table 4 and also plotted in a log-log fashion against literature $\mathrm{n}$-octanol/water partition coefficients of the respective phenols (Hansch and Leo (1979)) in Figure 3. It is evident from the widely spaced positions of $\mathrm{P}_{\mathrm{sc}}$ and $\mathrm{P}_{\mathrm{vt}}$ of phenol and 4-nitrophenol that permeability of these two compounds is controlled by the stratum corneum.

Estimated permeability coefficients for the viable tissue evidence some variability but are centered around $0.36 \mathrm{~cm} / \mathrm{hr}$, consistent with past experience with low molecular weight alkanols (Flynn et al. (1981)). It is notable, both from Table 4 and Figure 3 , that the permeability coefficients of the viable tissue and stratum corneum are of comparable magnitude for the more hydrophobic phenols. This is in accord with past experience (Flynn et al. (1981)) (Roberts et al. (1978)). It is evident that for the more hydrophobic phenols, the living, cellular epidermis and the dermis, limit absorption. These living layers also exert the sole resistance and offer a minimal protection from absorption of all compounds across damaged skin. The actual limiting permeability coefficient of the living stratum in man is likely to be 2 to 3 times higher than seen in these studies, or about $1 \mathrm{~cm} / \mathrm{hr}$, due to the fact that blood flowing through the superficial capillary plexus effectively reduces the thickness of the living tissue to be diffusionally negotiated.

With the exception of data for the nitrophenols, the overall data fit a pattern which suggests the rate 


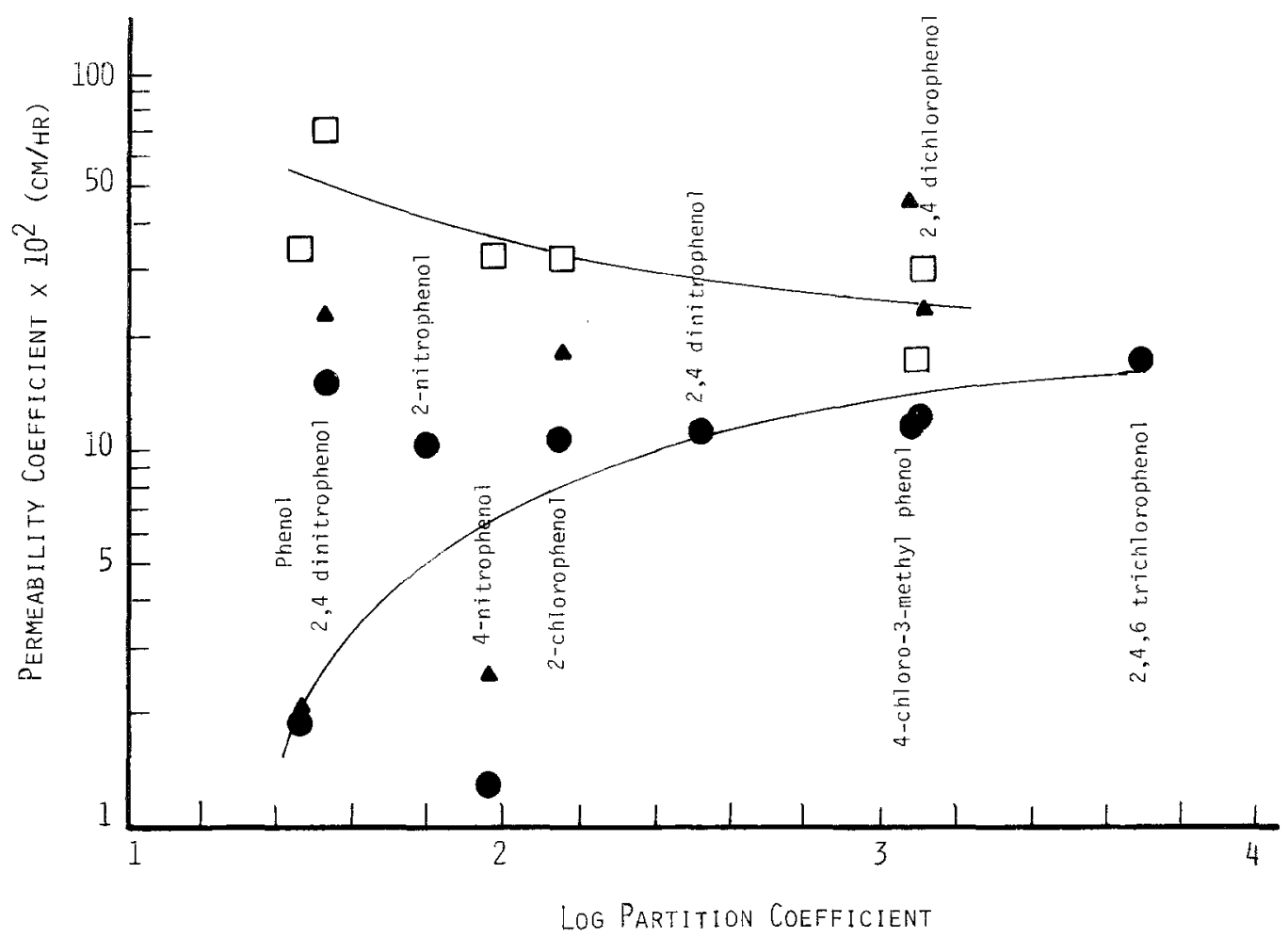

Fig. 3. Plot of $\log$ (permeability coefficient) vs $\log$ (partition coefficient, $n$-octanol/water); $\boldsymbol{\bullet}$, whole skin; $\boldsymbol{\Lambda}$, stratum corneum; and $\square$, viable tissue. There is no appreciable partitioning dependency to the permeability coefficients obtained on tape denuded skin. However, the permeability coefficients of whole skin of the more polar phenols, phenol and 4-nitrophenol, are much lower than for the denuded, a sure sign of stratum corneum control. Stratum corneum permeability coefficients are calculated by difference

controlling portion of the skin membrane systematically shifts from the stratum corneum to the living tissues as the compounds become more hydrophobic. Previously, Roberts et al. (1978) showed with human epidermis that alkanol and phenol data are internally consistent and, when taken together, describe this transition well. Neither the 2,4-dinitro phenol nor the 4-nitro phenol permeability coefficient fits comfortably into their scheme however, the former being too high and the latter too low based on their positions on the octanol/water scale of polarity. It is impossible to say at this time why these two compounds are outliers to what is otherwise a highly systematic pattern. Octanol/water partition coefficients may not properly reflect the lipophilicities of this pair with respect to the lipoidal phases of the skin. Self-association of the phenols in octanol and/or water or in the skin's phases might also account for their anomalous behavior.

\section{Permeability/pH Relationships}

In recognition of the strong inductive electronic effects of $\mathrm{Cl}$ and $\mathrm{NO}_{2}$ substituents on the acidities of phenols, 4-nitrophenol (pKa 7.15), 2,4-dinitrophenol (pKa 3.96), and 2,4,6-trichlorophenol ( $\mathrm{pKa}$ 6.0 ) were selected as particularly useful phenol analogs to explore $\mathrm{pH}$ influences on permeability. Dissociations of these particular phenols will be more influenced by the natural or man-induced variations in surface water $\mathrm{pH}$ than will dissociations of phenols which have $\mathrm{pKa}$ values greater than 8.0. When these phenols were applied to the skin in buffered solutions covering a range of $\mathrm{pH}$ 's bracketing the respective $\mathrm{pKa}$ values, they became less permeable as pH was increased (Figure 4), indicating ionization hinders mass transfer. Intrinsically lipophilic, acidic 2,4-dinitrophenol was highly permeable at $\mathrm{pH} 3$ and nearly impermeable at $\mathrm{pH} 7$. A 4-fold change in effective permeability coefficient for the highly lipophilic and less acidic trichlorophenol between pH 5 and 7.5 was noted; however, the permeability at $\mathrm{pH} 7.5$ was still high. While permeability drops off more or less steeply as ionization of the phenols is induced, there is still measurable flux at the highest $\mathrm{pH}$ values studied. Apparently, on this basis, there is a limited flux of phenolic anions, although the data are not sufficient to factor out the contributions of free and ionic species to the flux. This suggests there is a means 


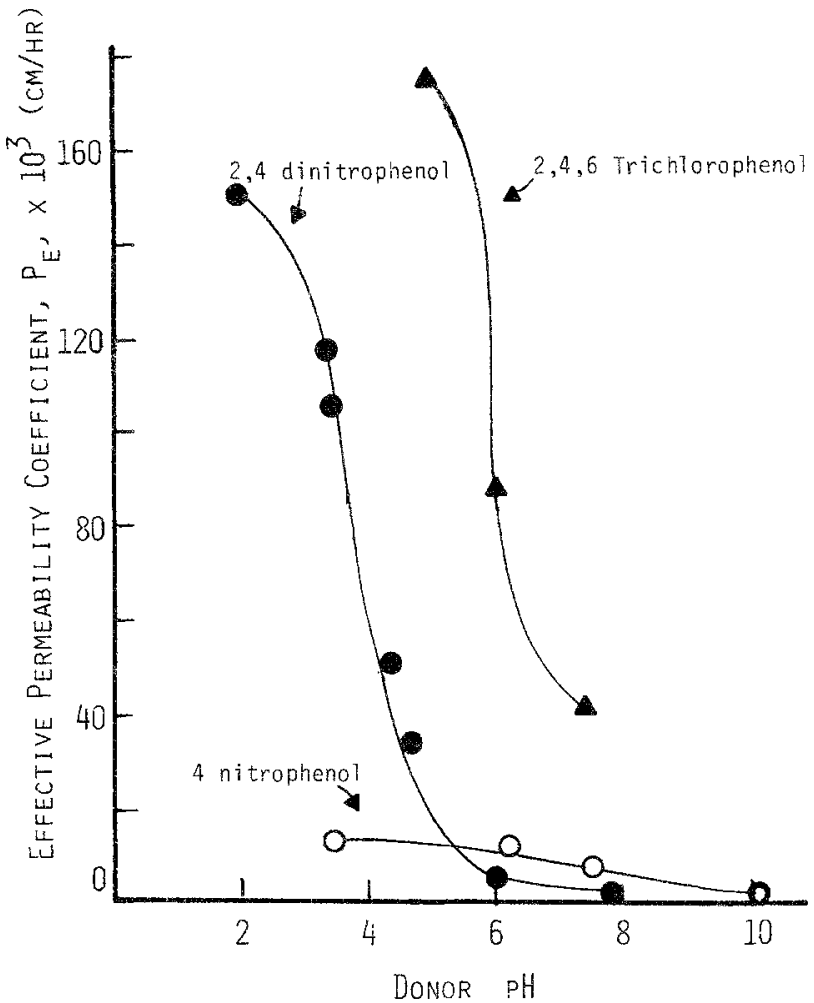

Fig. 4. Effective permeability coefficient of whole skin vs donor $\mathrm{pH}$. Receiver side $\mathrm{pH}$ is alkaline. Intrinsic partition coefficients were determined in $\mathrm{n}$-octanol/aqueous solution $\left(\mathrm{pH} \gg \mathrm{pK}_{\mathrm{a}}\right)$, i.e., 1.96 for 4-nitrophenol $(O) ; 1.52$ for 2,4 dinitrophenol (@); and 3.69 for 2,4,6-trichlorophenol (4)

through the horny layer which does not involve the equivalent of oil/water partitioning.

\section{Comparison of Mouse Data With Human Data and Risk Projections}

The principal purpose of this study was to gather basic data for estimation of human risk of absorption of USEPA identified phenolic pollutants. It was pointed out that lag times are short and therefore steady states of permeation will likely be obtained by the compounds during typical periods of water exposure. It is reassuring that the obtained intrinsic (free acid) permeability coefficients for the hairless mouse (model) are in accord with similar data obtained by others (Roberts et al. (1978)) with human epidermis (Table 5). While the overlap between studies involves only four compounds, it is readily seen that all values are of similar magnitude with no mouse parameter being more than a factor of two different from its human epidermal counterpart. Therefore, it seems safe to project a limiting permeability coefficient through intact human skin
Table 5. Comparison of permeability coefficients for various phenol analogs in hairless mouse and human skin at $37^{\circ} \mathrm{C}$

\begin{tabular}{lcc}
\hline & $\mathrm{P}_{\mathrm{e}} \times 10^{3} \mathrm{~cm} / \mathrm{hr}$ & \\
\cline { 2 - 3 } Permeant & Hairless mouse & Human $^{\mathrm{a}}$ \\
\hline Phenol & 18.8 & 21.1 \\
2-Chlorophenol & 106.5 & 61.9 \\
2,4,6-Trichlorophenol & 174.0 & 108. \\
4-Chloro-3-cresol & 118.9 & 108. \\
\hline
\end{tabular}

${ }^{a}$ Calculated from literature values (Behl et al 1984; Morrison and Boyd 1959)

for the phenols on the order of $\sim 0.15 \mathrm{~cm} / \mathrm{hr}$. The permeability coefficients may be lower than this by a factor of ten or more if the phenol is polar or ionized. When the skin is denuded (stripped), the $\mathrm{O} / \mathrm{W}$ partitioning dependency of phenolic permeability is completely lost and permeability coefficients of $\sim 0.36 \mathrm{~cm} / \mathrm{hr}$ are seen. Therefore, a value of 0.5 $\mathrm{cm} / \mathrm{hr}$ can be taken as a safe, conservative upper permeability coefficient limit to use in risk analysis. This value leads one to the conclusion that after about a half hour's exposure an upper, attainable whole body absorption rate of a human adult totally immersed in water contaminated with $1 \mathrm{ppm}$ phenol would be approximately $10 \mathrm{mg} / \mathrm{hr}$ or almost $250 \mathrm{mg} /$ day. This estimate assumes an adult surface area of $2 \mathrm{~m}^{2}$, which would be for a large $(\sim 200 \mathrm{lb})$ adult. Reduction of either the involved area, the contaminating concentration of the phenol, or the phenolic permeability coefficient produces exactly proportional reductions in the amounts absorbed. For example, the total body area absorption rate of a 1 ppm solution of phenol estimated from phenol's permeability coefficient determined in this research would be $0.38 \mathrm{mg} / \mathrm{hr}$ or $9 \mathrm{mg} / \mathrm{day}$.

One last observation of possible significance to toxicity of the phenols is that, using HPLC, they were not metabolized or conjugated during their diffusive transport through the skin. They are known to be partially converted in the gastrointestinal mucosa to more easily eliminated, less toxic conjugates as glucuronides after their oral ingestion. Therefore, it is likely that amounts absorbed through the skin are more toxic than equivalent amounts by the oral route. Not only does this have bearing on the assessment of toxicity of phenols, but in a general way, it shows that the toxicologic data upon which the risk assessments are to be based must be evaluated for their appropriateness relative to the route of absorption.

Acknowledgments. This research was supported by USEPA Grant CA-GR809229. Thanks are extended to E. R. Squibb and 
its staff who assisted in the preparation of parts of the manuscript and the illustrations.

\section{References}

Barlin GB, Perrin, DB (1966) Prediction of the strengths of organic acids. Quart Rev 20:75-100

Behl CR, Flynn GL, Linn EE, Smith WM (1984) Percutaneous absorption of corticosteroids: Age, site, and skin-sectioning influences on rates of permeation of hairless mouse skin by hydrocortisone. J Pharm Sci 73:1287-1290

Behl CR, Linn EE, Flynn GL, Pierson CL, Higuchi WI, Ho NFH (1983) Permeation of skin and eschar by antiseptics I: Baseline studies with phenol. J Pharm Sci 73:391-397

Durrheim H, Flynn GL, Higuchi WI, Behl CR (1980) Permeation of hairless mouse skin I: Experimental methods and comparison with human epidermal permeation by alkanols. J Pharm Sci 69:781-785
Flynn GL, Durrheim H, Higuchi WI (1981) Permeation of hairless mouse skin II: Membrane sectioning techniques and influence on alkanol permeabilities. J Pharm Sci 70:52-56

Hansch C, Leo AJ (1979) Substituent constants for correlation analysis in chemistry and biology, John Wiley \& Sons, New York, $339 \mathrm{pp}$

Morrison RT, Boyd RN (1959) Organic chemistry. Allyn and Bacon, Boston, pp 585-588

Roberts MS, Anderson RA, Swarbrick J (1977) Permeation of human epidermis to phenolic compounds. J Pharm Pharmacol 29:677-683

Roberts MS, Anderson RA, Swarbrick J. Moore DE (1978) The percutaneous absorption of phenolic compounds: The mechanism of diffusion across the stratum corneum. J Pharm Pharmacol 30:486-490

Manuscript received January 30, 1986 and in revised form April 21,1986 